\title{
Digital PCR Technology for Detection of Palm-Infecting Phytoplasmas Belonging to Group 16SrIV that Occur in Florida
}

Brian W. Bahder, ${ }^{\dagger}$ Ericka E. Helmick, and De-Fen Mou, Department of Entomology and Nematology, University of Florida, Fort Lauderdale Research and Education Center (FLREC), Davie 33314-7719; Nigel A. Harrison, Department of Plant Pathology, University of Florida, FLREC; and Robert Davis, Molecular Plant Pathology Laboratory, United States Department of Agriculture-Agricultural Research Service, Beltsville, MD 20705

\begin{abstract}
Phytoplasmas are an economically important group of plant pathogens that negatively impact a wide variety of plants in agricultural and natural ecosystems. In Florida, palm trees are essential elements in the nursery and landscaping industries that suffer from diseases caused by phytoplasmas that are related to each other but are classified in two different subgroups, 16SrIV-A and 16SrIV-D. In this study, a TaqMan assay was developed for digital polymerase chain reaction (dPCR) to detect both palm-infecting phytoplasmas found in Florida. When compared with real-time PCR assays and nested PCR assays, dPCR was capable of detecting the phytoplasmas at much lower concentrations than was possible by

using real-time PCR and nested PCR. Additionally, the assay was capable of detecting 16SrIV-B phytoplasma as well as isolates representing the $16 \mathrm{SrI}$ and $16 \mathrm{SrIII}$ phytoplasma groups. Due to sequence identity of primer annealing regions across diverse phytoplasmas, the assay is likely to be successful for detection of a wide variety of phytoplasmas. The increased sensitivity of this dPCR assay over real-time PCR will allow for earlier detection of phytoplasma infection in palm trees, as well as for screening of salivary glands of candidate insect vector species. These advantages should aid timely management decisions to reduce disease spread and rapid determination of phytoplasma transmission by vectors.
\end{abstract}

Phytoplasmas are an economically important group of plant pathogens responsible for over 700 serious diseases in plants (Weintraub and Beanland 2006). Phytoplasma classification into a series of groups and subgroups is based on results from restriction fragment length polymorphism (RFLP) analysis of the $16 \mathrm{~S}$ gene. The groups currently identified are named sequentially from 16SrI to 16SrXXXIII (Bertaccini et al. 2014). Different groups have different biological properties, including symptoms, vectors, and host ranges. The $16 \mathrm{Sr}$ group that infects palm trees, causing lethal declines, is the 16SrIV group and consists of six subgroups: 16SrIV-A, -B, -C, -D, -E, and -F (Vázquez-Euán et al. 2011).

Historically, lethal yellowing (LY) has been the phytoplasma disease caused by the 16SrIV-A subgroup responsible for the death of many coconut palm trees (Cocos nucifera) in Florida. Additionally, LY is known to infect over 30 species of palm in the state of Florida, including various species of date palm (Phoenix spp.) (Harrison and Elliott 2015) which are of high economic value. The first appearance of LY in Florida was recorded in 1955 (Corbett 1959) in Key West and first appeared on the Florida mainland in the early 1970s (Thomas 1974). Currently, LY is restricted to the southern portion of the state of Florida, ranging as far north as Manatee County on the west coast and Indian River County on the east coast (Harrison and Elliott 2015). Until 2006, LY was the only known phytoplasma disease to infect palm trees in Florida. In 2006, specimens of Phoenix canariensis, $P$. dactylifera, and $P$. sylvestris tested positive for the 16SrIV-D phytoplasma (Harrison et al. 2008). This phytoplasma disease, currently termed lethal bronzing disease (LBD) and synonymous with Texas Phoenix palm decline, was first reported in Phoenix spp. of palm in Texas (McCoy et al. 1980). This disease was initially seen on the western coast of Florida and has subsequently been found through much of the central and southern counties, with

${ }^{\dagger}$ Corresponding author: B. W. Bahder; E-mail: bbahder@ufl.edu

Funding: Funding for this research was provided through the Farm Bill Cooperative Agreement 16-8130-0148-CA and through the University of Florida startup research funds provided to B. W. Bahder. Additional funds were also provided by the Florida Nursery, Growers and Landscape Association.

Accepted for publication 11 December 2017.

() 2018 The American Phytopathological Society sporadic occurrence in the northern portion of the state (Harrison and Elliott 2016).

Various aspects of the biology of LY, which are shared by LBD, make it difficult to study. Some of the biggest challenges include maintaining constant cultures of the phytoplasma for genomics and vector studies, the sporadic nature and length of times between outbreaks, rapid death of palm upon onset of symptoms, and difficulty in obtaining enough genetic material from palm tissue. The latter issue is due to the need to take trunk tissue because leaf material is often too high to sample and the low titer of phytoplasma in palm trunks relative to the spearleaf (Harrison et al. 1994). Additionally, death of the palm generally occurs within months of the onset of symptoms and it is at this stage that the palm is sampled. This raises the issue of the duration of time between infection and the onset of symptoms and what titer is present during this latent phase. Another unknown aspect that is crucial for management is understanding the titer of phytoplasma in the leaf tissue and knowing how long after infection before the plant becomes a source of inoculum, where a vector can successfully acquire the phytoplasma. Levels needed for a vector may be lower than what is detectable in leaf tissue, meaning that transmission to new plants may occur before a palm can be confirmed positive by polymerase chain reaction (PCR) or real-time (quantitative) PCR (qPCR). Being able to detect the phytoplasma in palm tissue, either the trunk or leaf, early in the infection (i.e., before symptoms appear) would be a benefit to stakeholders because earlier detection can lead to a more rapid response in terms of implementing management strategies that can significantly reduce or eliminate spread of the disease in the field, resulting in lower economic losses.

Traditionally, detection and classification of phytoplasmas in palm has been done by standard PCR and nested PCR (initial detection) followed by RFLP analysis (identification or classification) (Harrison et al. 1994; Tymon et al. 1998). Although reliable for identification and classification, this technique is not practical for low levels of phytoplasma that would be anticipated at very early stages of infection or within vector salivary glands. Recently, qPCR has become a useful technique for increasing the sensitivity and specificity for detecting palm-infecting phytoplasmas (Córdova et al. 2014) and, when combined with high-resolution melt analysis (Bahder et al. 2017), can differentiate various subgroups, eliminating the need for nested reactions and RFLP. A relatively new technology in the field of plant pathology is digital PCR (dPCR) which has only recently begun to be adapted to plant pathogens and agricultural systems (Bahder et al. 2016; Dreo et al. 2014; Rački et al. 2014). In the 
medical field, $\mathrm{dPCR}$ has been demonstrated to be more sensitive than qPCR (Miotke et al. 2014). If the increase in sensitivity of dPCR translates to plant pathogens, adapting dPCR would be greatly beneficial in detecting phytoplasmas in lower concentrations than was previously possible, allowing for the identification of early infections and rapid screening of candidate vector species. By being able to detect infections earlier, management decisions can be implemented sooner and, thus, reduce the potential of further spread in the field. Also, dPCR was used to aid in elucidating the vector of Grapevine red blotch-associated virus (Bahder et al. 2016) and could be useful in identifying the vector of LBD.

The primary objective of this study was to design a successful dPCR assay that is capable of detecting both LY and LBD phytoplasmas. A secondary objective was to evaluate the overall sensitivity of dPCR for detection of palm-infecting phytoplasmas as compared with both qPCR and standard nested PCR detection assays to evaluate its sensitivity to other novel and established protocols. Developing a robust TaqMan Assay with increased sensitivity would be beneficial to researchers and stakeholders by aiding in vector discovery as well as detecting infections earlier in the disease cycle.

\section{Materials and Methods}

Isolate selection and serial dilutions. Isolates of LY and LBD used in this study were selected from samples stored at the Fort Lauderdale Research and Education Center (FLREC) that had previously tested positive for the 16SrIV-A and 16SrIV-D phytoplasmas and were confirmed by sequencing. The LY isolate was obtained from an infected $C$. nucifera sampled at FLREC (isolate ID: LYJT-EF)

Table 1. Total DNA measured in all serial dilutions for both the 16SrIV-A, 16SrIV-B, and 16SrIV-D isolates and the healthy control (HC)

\begin{tabular}{|c|c|c|c|c|c|c|c|}
\hline \multirow[b]{2}{*}{ Dilution $(\%)^{\mathrm{a}}$} & \multirow[b]{2}{*}{ Factor ${ }^{b}$} & \multicolumn{6}{|c|}{ 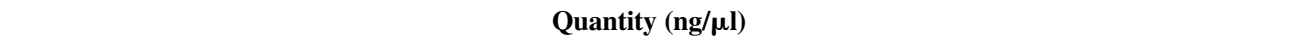 } \\
\hline & & 16SrIV-A & 16SrIV-B & 16SrIV-D & $\mathrm{HC}$ & $16 \mathrm{SrI}$ & 16SrIII \\
\hline 100 & 1 & $1,320 \pm 50.2$ & $80.0 \pm 0.32$ & $58.8 \pm 4.0$ & $32.5 \pm 2.9$ & $1,992 \pm 86.0$ & $1,742 \pm 74.6$ \\
\hline 10 & $1 e^{-1}$ & $101 \pm 6.3$ & $6.8 \pm 0.12$ & $5.8 \pm 1.1$ & $2.9 \pm 0.8$ & $723.9 \pm 21.2$ & $547.3 \pm 19.7$ \\
\hline 1 & $1 \mathrm{e}^{-2}$ & $8.6 \pm 1.0$ & $0.7 \pm 0.06$ & $0.7 \pm 0.1$ & $0.4 \pm 0.1$ & $79.8 \pm 0.7$ & $48.7 \pm 5.4$ \\
\hline 0.1 & $1 \mathrm{e}^{-3}$ & $0.9 \pm 0.2$ & 0.0 & 0.0 & 0.0 & $9.4 \pm 0.2$ & $5.3 \pm 0.1$ \\
\hline 0.01 & $1 \mathrm{e}^{-4}$ & 0.0 & 0.0 & 0.0 & 0.0 & $0.7 \pm 0.0$ & $0.4 \pm 0.0$ \\
\hline 0.001 & $1 e^{-5}$ & 0.0 & 0.0 & 0.0 & 0.0 & 0.0 & 0.0 \\
\hline 0.0001 & $1 \mathrm{e}^{-6}$ & 0.0 & 0.0 & 0.0 & 0.0 & 0.0 & 0.0 \\
\hline 0.00001 & $1 e^{-7}$ & 0.0 & 0.0 & 0.0 & 0.0 & 0.0 & 0.0 \\
\hline 0.000001 & $1 \mathrm{e}^{-8}$ & 0.0 & 0.0 & 0.0 & 0.0 & 0.0 & 0.0 \\
\hline 0.0000001 & $1 \mathrm{e}^{-9}$ & 0.0 & 0.0 & 0.0 & 0.0 & 0.0 & 0.0 \\
\hline
\end{tabular}

a Percentage of original extract.

${ }^{\mathrm{b}}$ Dilution factor.

16SrIV-A (KX982668)

16SrIV-B (U18753.2)

16SrIV-C (X80117.1)

16SrIV-D (AF434989)

16SrI-A (AY389828.2)

16SrII-A (JX403944.1)

16SrIII-A (JN903385.1)

16SrV-A (AY197658.1)

16SrVI-A (AF409070.1)

16SrVII-A (AF105317.1)

16SrVIII-A (AF248956.1)

16SrIX-A (KJ817873.1)

16SrX-A (AF248958.1)

16SrXI-A (AB052873.1)

16SrXII (AY739654.1)

16SrXIII-A (AF248960.1)

16SrXIV-A (AJ550984.1)

16SrXV-A (AF147708.1)

16SrXVI-A (AY725228.1)

16SrXVII-A (AY725234.1)

16SrXVIII-A (DQ174122.1)

16SrXIX-A (AB054986.1)

16SrXX-A (KP851770.1)

16SrXXI-A (AJ310849.2)

16SrXXII-A (KF751387.1)

16SrXXIII (AY083605.1)

16SrXXIV-A (AF509322.1)

16SrXXV-A (AF521672.1)

16SrXXVI-A (AJ539179.1)

16SrXXIX-A (EF666051.1)

16SrXXX-A (FJ432664.1)

16SrXXXI-A (HQ225630.1)

16SrXXXII-A (EU371934.2)

16SrXXXIII-A (AY135523.1)

Fibrobacter succinogenes (NR118361.1)

Staphylococcus aureus (EF463060.1)
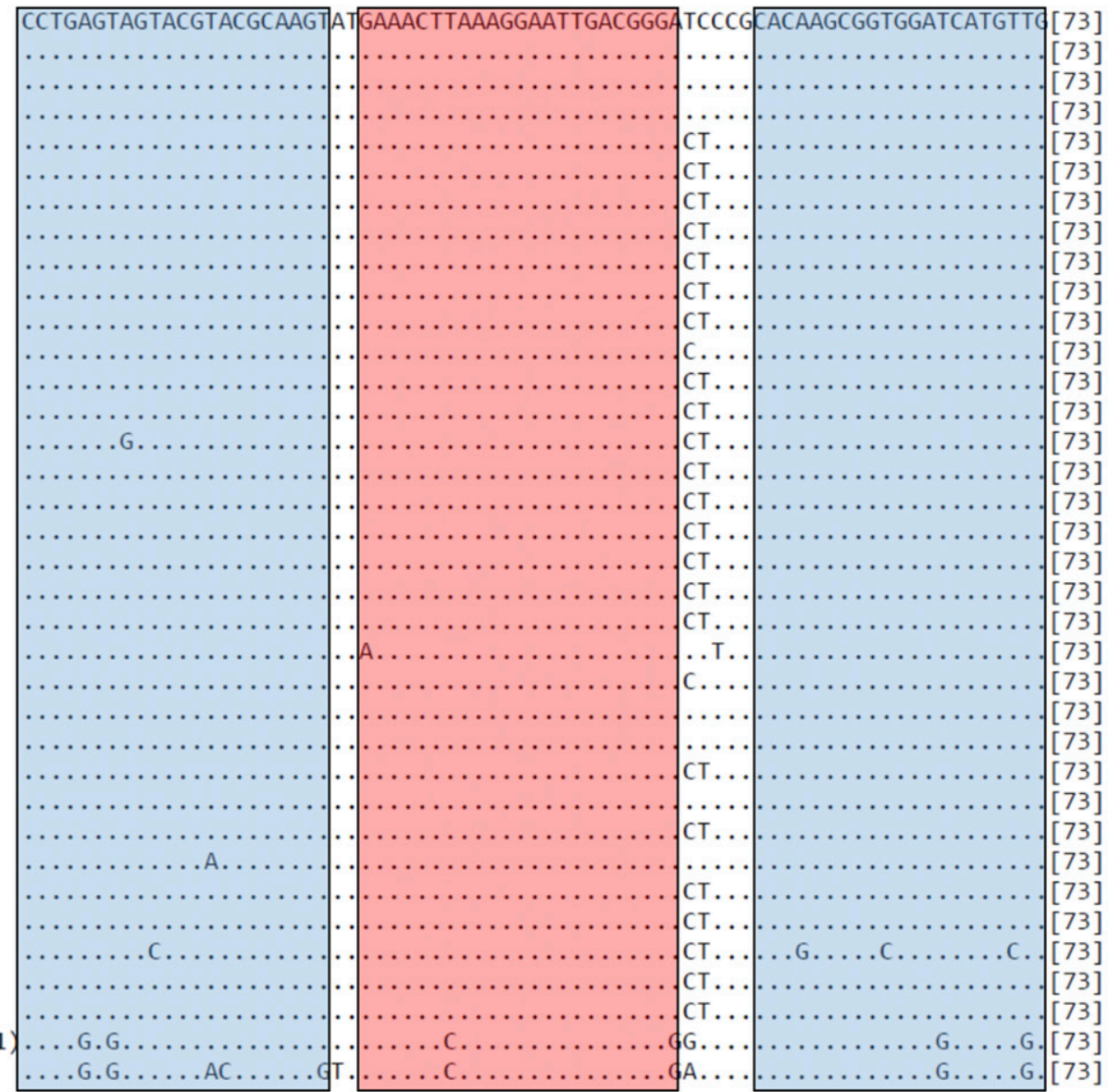

Fig. 1. Sequence alignment of a region of the $16 \mathrm{~S}$ gene targeted by the TaqMan Custom Copy Assay for phytoplasma strains representing each $16 \mathrm{Sr}$ taxonomic group compared with the palm lethal decline phytoplasmas, 16SrIV, and eubacterial outgroups in the $5^{\prime}$-to-3' direction. 
and the LBD isolate was obtained from an infected Sabal palmetto sampled in Manatee County, FL (isolate ID: Sab1). Additionally, an isolate of the 16SrIV-B phytoplasma taken from an infected coyol palm (Acrocomia aculeate) in Honduras (Coy+12) (accession number DQ321818) was used to determine use of the assay against other 16SrIV phytoplasmas not known from Florida but present in the Caribbean and that have potential for introduction. A Sabal palm (isolate ID: Sabal4) that had previously tested negative for phytoplasma infection was used as a healthy control. The total DNA extractions for each of the isolates tested were serially diluted nine times ( $10 \times$ dilution factor), using Qiagen Buffer AE (Qiagen, Inc.), allowing for 10 different concentrations of each isolate. Total DNA $(1 \mu \mathrm{l})$ and each of the dilutions for all isolates was quantified using the NanoDrop ${ }^{\mathrm{TM}}$ Lite spectrophotometer (Thermo Scientific). Two isolates of phytoplasmas belonging to the 16SrI (Aster Yellows) group and the 16SrIII (Western-X) group were also diluted to the optimal concentration and tested to evaluate the utility of the assay on other phytoplasmas belonging to other $16 \mathrm{Sr}$ groups.

TaqMan assay design and $\mathrm{APCR}$ parameters. To obtain the primers and probe necessary for dPCR, sequence data for the entire $16 \mathrm{~S}$ gene for the 16SrIV-D phytoplasma (Accession number AF434989) was uploaded into Thermo-Fishers web-based portal using the custom copy number option. The region selected was aligned with the same region of the $16 \mathrm{SrIV}-\mathrm{A}$ phytoplasma to ensure sequence identity between the two strains at the primer and probe regions. This region was also aligned with all other subgroups of the 16SrIV taxonomic group available on GenBank, as well as the A subgroup from each of the existing 16Sr groups and two outgroups, Fibrobacter succinogenes and Staphylococcus aureus. This alignment process was to provide insight to the range of phytoplasmas that this assay could detect and to ensure that it would not amplify nonphytoplasma bacterial DNA. The probe was labeled with the $5^{\prime}$ reporter dye, 6-carboxyfluorescein (FAM), and a 3' quencher, nonfluorescent

Table 2. Digital polymerase chain reaction data for the serial dilution of the 16SrIV-A isolate

\begin{tabular}{lcrccc}
\hline Dilution & Total wells & $(+)$ Wells & $(-)$ Wells & Copies/ $\boldsymbol{\mu l}$ & Precision $(\%)$ \\
\hline 1 & 16,887 & 16,887 & 0 & N/A & N/A \\
$1 \mathrm{e}^{-1}$ & 17,667 & 17,667 & 0 & N/A & N/A \\
$1 \mathrm{e}^{-2}$ & 17,791 & 9,612 & 8,179 & $1,029.20$ & 1.48 \\
$1 \mathrm{e}^{-3}$ & 16,212 & 1,421 & 14,791 & 121.55 & 5.34 \\
$1 \mathrm{e}^{-4}$ & 17,596 & 168 & 17,428 & 12.71 & 16.33 \\
$1 \mathrm{e}^{-5}$ & 17,538 & 15 & 17,523 & 1.13 & 65.88 \\
$1 \mathrm{e}^{-6}$ & 16,816 & 6 & 16,810 & 0.47 & 122.59 \\
$1 \mathrm{e}^{-7}$ & 17,122 & 0 & 17,122 & N/A & N/A \\
$1 \mathrm{e}^{-8}$ & 17,912 & 0 & 17,912 & N/A & N/A \\
$1 \mathrm{e}^{-9}$ & 16,545 & 0 & 16,545 & N/A & N/A \\
Healthy & 17,544 & 0 & 17,544 & N/A & N/A \\
Water & 18,909 & 0 & 18,909 & N/A & N/A \\
\hline
\end{tabular}

${ }^{\mathrm{a}} \mathrm{N} / \mathrm{A}=$ not available.

Table 3. Digital polymerase chain reaction data for the serial dilution of the 16SrIV-B isolate ${ }^{\mathrm{a}}$

\begin{tabular}{lcrrcc}
\hline Dilution & Total wells & $(+)$ Wells & $(-)$ Wells & Copies/ $\boldsymbol{\mu l}$ & Precision $(\%)$ \\
\hline 1 & 17,001 & 17,001 & 0 & N/A & N/A \\
$1 \mathrm{e}^{-1}$ & 16,751 & 16,524 & 227 & 6,003 & 3.27 \\
$1 \mathrm{e}^{-2}$ & 16,968 & 11,101 & 5,863 & $1,413.4$ & 1.98 \\
$1 \mathrm{e}^{-3}$ & 17,959 & 1,756 & 16,203 & 136.33 & 4.79 \\
$1 \mathrm{e}^{-4}$ & 17,382 & 232 & 17,150 & 17.8 & 13.73 \\
$1 \mathrm{e}^{-5}$ & 17,877 & 21 & 17,856 & 1.6 & 53.37 \\
$1 \mathrm{e}^{-6}$ & 17,792 & 2 & 17,790 & N/A & N/A \\
$1 \mathrm{e}^{-7}$ & 17,630 & 0 & 17,630 & N/A & N/A \\
$1 \mathrm{e}^{-8}$ & 17,914 & 0 & 17,914 & N/A & N/A \\
$1 \mathrm{e}^{-9}$ & 18,112 & 0 & 18,112 & N/A & N/A \\
Healthy & 17,423 & 0 & 17,423 & N/A & N/A \\
Water & 17,222 & 0 & 17,222 & N/A & N/A \\
\hline
\end{tabular}

${ }^{\mathrm{a}} \mathrm{N} / \mathrm{A}=$ not available. quencher (NFQ). dPCR assays were performed in $14.5 \mu$, as per the manufacturer's instructions. Each reaction comprised $6 \mu \mathrm{l}$ of DNA template, $7.25 \mu$ l of QuantStudio 3D Digital PCR Master Mix v2, $0.725 \mu l$ of the custom copy number TaqMan assay, and $1.525 \mu \mathrm{l}$ of water. Reaction mixtures were loaded on QuantStudio 3D Digital PCR 20K Chips v2 using the QuantStudio 3D Digital PCR Chip Loader and run on a ProFlex Base PCR System. Thermal cycling conditions consisted of an initial denaturation stage of $95^{\circ} \mathrm{C}$ for $10 \mathrm{~min}$., followed by 35 cycles of denaturation at $95^{\circ} \mathrm{C}$ for $30 \mathrm{~s}$, annealing at $60^{\circ} \mathrm{C}$ for $30 \mathrm{~s}$, and extension at $72^{\circ} \mathrm{C}$ for $30 \mathrm{~s}$, and a final extension of $5 \mathrm{~min}$. at $72^{\circ} \mathrm{C}$. End-point fluorescent data were collected on a QuantStudio 3D Digital PCR System and analyzed using the QuantStudio AnalysisSuite Cloud Software (https://www.thermofisher. com/us/en/home/life-science/pcr/digital-pcr/quantstudio-3d-digital-pcrsystem/quantstudio-3d-software.html).

Real-time PCR assay parameters. Isolate dilutions used for dPCR assays were also screened by real-time PCR. The primer sequences used in the real-time assays were LY16S-LSF (5'-CGTGTCGTGAGATGTTAGGTTAAGT-3'), LY16S-LSR (5'GCTAAAGTCCCCACCATAACGT-3'), and LY16S-Probe (5'CCCCTGTCGTTAATTG- $3^{\prime}$ ) labeled on the $5^{\prime}$ end with FAM and on the $3^{\prime}$ end with NFQ quencher (Córdova et al. 2014). Assays were performed on a StepOnePlus Real-Time PCR System (Applied Biosystems, Inc.) in 20- $\mu$ l reactions. Each reaction consisted of $1.0 \mu \mathrm{l}$ of template, $0.15 \mu \mathrm{M}$ each primer, $0.3 \mu \mathrm{M}$ FAM-labeled probe, $2 \%$ polyvinylpyrolidine (PVP-40; molecular weight 40,000), and $51.5 \%$ TaqMan Universal Master Mix II, with UNG (Applied Biosystems, Inc.), with the remaining volume made up with water. Thermal cycling conditions were as follows: $10 \mathrm{~min}$ of initial denaturation at $95^{\circ} \mathrm{C}$, followed by 35 cycles of denaturation for $30 \mathrm{~s}$ at $95^{\circ} \mathrm{C}$, annealing for $30 \mathrm{~s}$ at $60^{\circ} \mathrm{C}$, and extension at $72^{\circ} \mathrm{C}$ for $30 \mathrm{~s}$.

Nested-PCR assay parameters. Nested-PCR assays were performed on the serial dilutions to determine detection sensitivity of the standard phytoplasma detection protocol as compared with $\mathrm{dPCR}$ and real-time PCR protocols. Standard laboratory detection of LY and LBD phytoplasmas consist of a primary and nested PCR assay. Primers for the primary PCR were forward primer P1m ( $5^{\prime}-$ TCCTGGGCTCAGGATTAAC-3') (Harrison et al. 2008) and reverse primer LY16-23Sr (5'-TTGAGAATTTACGTTGTTTATCTAC-3') (Harrison et al. 2002a). PCR (final volume of $25 \mu \mathrm{l}$ ) consisted of $5 \times$ Green GoTaq Flexi Buffer, $25 \mathrm{mM} \mathrm{MgCl} 2,200 \mu \mathrm{M}$ dNTP, $0.5 \mu \mathrm{M}$ each primer, 2\% PVP-40, $1.5 \mathrm{U}$ of GoTaq Flexi DNA polymerase, and $2.0 \mu \mathrm{l}$ of each DNA template, with the final volume made up with Ultrapure sterile water. Thermocycling conditions for the primary PCR consisted of an initial denaturation at $95^{\circ} \mathrm{C}$ for $90 \mathrm{~s}$; followed by $34 \mathrm{cy}-$ cles of denaturation at $95^{\circ} \mathrm{C}$ for $30 \mathrm{~s}$, annealing at $60^{\circ} \mathrm{C}$ for $60 \mathrm{~s}$, and extension at $72^{\circ} \mathrm{C}$ for $120 \mathrm{~s}$; and a final extension stage of $72^{\circ} \mathrm{C}$ for 8 $\min$. The nested PCR were the same as for the primary, with the exception of the primers and the amount of template DNA. The nested PCR primers were LY16Sf2 (5'-AACGGGTGAGTAACACGTAAG-3') and LY16-23Sr2 (5'-TTAGACTGGTGGGCCTAAATG-3') (Harrison

Table 4. Digital polymerase chain reaction data for the serial dilution of the 16SrIV-D isolate ${ }^{\mathrm{a}}$

\begin{tabular}{lcrrrc}
\hline Dilution & Total wells & $(+)$ Wells & $(-)$ Wells & Copies/ $\boldsymbol{\mu l}$ & Precision $(\%)$ \\
\hline 1 & 17,224 & 17,224 & 0 & N/A & N/A \\
$1 \mathrm{e}^{-1}$ & 17,306 & 17,074 & 232 & $5,905.10$ & 3.13 \\
$1 \mathrm{e}^{-2}$ & 17,979 & 8,378 & 9,601 & 833.55 & 2.21 \\
$1 \mathrm{e}^{-3}$ & 18,401 & 1,131 & 17,270 & 84.03 & 6.00 \\
$1 \mathrm{e}^{-4}$ & 16,797 & 129 & 16,668 & 10.21 & 18.84 \\
$1 \mathrm{e}^{-5}$ & 17,435 & 29 & 17,406 & 2.21 & 43.90 \\
$1 \mathrm{e}^{-6}$ & 15,214 & 3 & 15,211 & $8.71 \mathrm{e}^{-2}$ & 609.93 \\
$1 \mathrm{e}^{-7}$ & 16,394 & 0 & 16,394 & $\mathrm{~N} / \mathrm{A}$ & $\mathrm{N} / \mathrm{A}$ \\
$1 \mathrm{e}^{-8}$ & 17,529 & 0 & 17,529 & N/A & N/A \\
$1 \mathrm{e}^{-9}$ & 18,031 & 0 & 18,031 & N/A & N/A \\
Healthy & 18,222 & 0 & 18,222 & N/A & N/A \\
Water & 17,459 & 0 & 17,459 & N/A & N/A \\
\hline
\end{tabular}

${ }^{\mathrm{a}} \mathrm{N} / \mathrm{A}=$ not available. 
et al. 2002b). The DNA template for the nested PCR consisted of $1.0 \mu \mathrm{l}$ of undiluted primary PCR product. The thermocycling conditions for the nested PCR consisted of an initial denaturation at $94^{\circ} \mathrm{C}$ for $60 \mathrm{~s}$; followed by 34 cycles of denaturation at $95^{\circ} \mathrm{C}$ for $60 \mathrm{~s}$, annealing at $60^{\circ} \mathrm{C}$ for $120 \mathrm{~s}$, and extension at $72^{\circ} \mathrm{C}$ for $180 \mathrm{~s}$; and a final extension stage of $72^{\circ} \mathrm{C}$ for $7 \mathrm{~min}$. All thermocycling was performed using a Bio-Rad T100 Thermal Cycler (Bio-Rad Laboratories, Inc.). Resulting PCR products were electrophoresed on a $1 \%$ agarose gel, stained using GelRed Nucleic Acid Stain (Biotium, Inc.), and visualized using ultraviolet light.

\section{Results}

Isolate dilution concentrations and sequence data. The total DNA measured for each dilution for LBD, LY, and the 16SrIV-B phytoplasmas is presented in Table 1. Additionally, concentrations for dilutions of the $16 \mathrm{SrI}$ and $16 \mathrm{SrIII}$ phytoplasmas are included in Table 1. The region selected for primer design was a 73-bp product, starting at nucleotide 872 of the $16 \mathrm{~S}$ gene and ending at nucleotide 945. Based on the sequence alignment of the primer regions and the probe annealing location, there is $100 \%$ identity among all strains of the 16SrIV phytoplasmas recorded from diseased palm trees (Fig. 1) of the target region in the dPCR assay. Also, both the primer and probe regions share a high level of identity with other $16 \mathrm{Sr}$ group phytoplasmas outside of the 16SrIV group (Fig. 1). The primer sequences for the TaqMan assay were 5'-CCTGAGTAGTACGTACGCAAGT-3' (forward) and 5'-CAACATGATCCACCGCTTGTG-3' (reverse). The probe sequence was 5'-FAM-TCCCGTCAATTCCTTTAAGTTTC-3'. The probe is the reverse compliment to the region highlighted in Figure 1, which is in a $5^{\prime}$-to-3' direction.

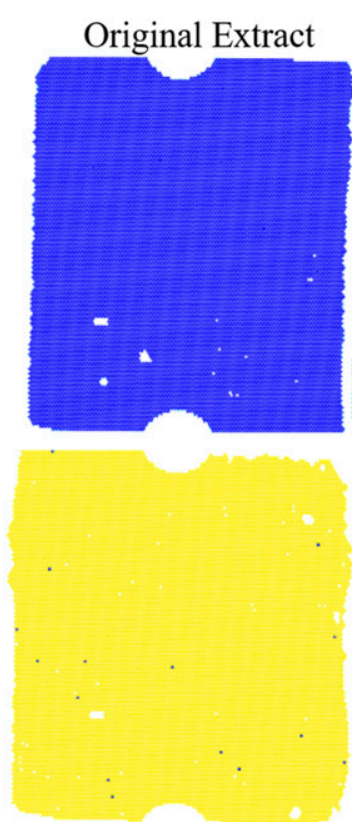

$1 \mathrm{e}-5$
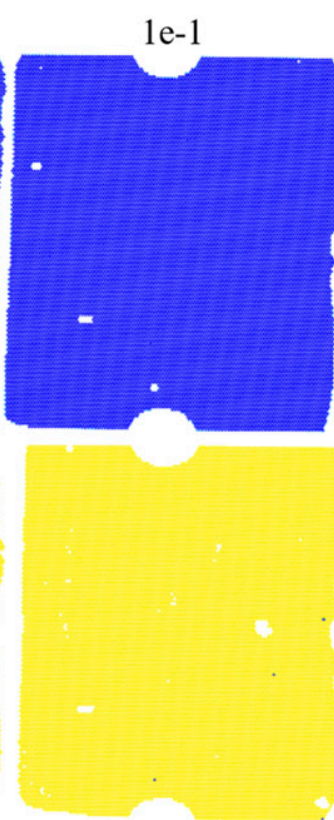

1e-6
$1 \mathrm{e}-2$
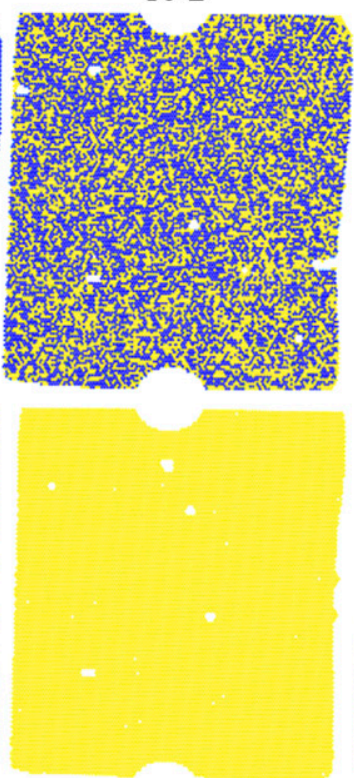

1e-7
$1 \mathrm{e}-3$

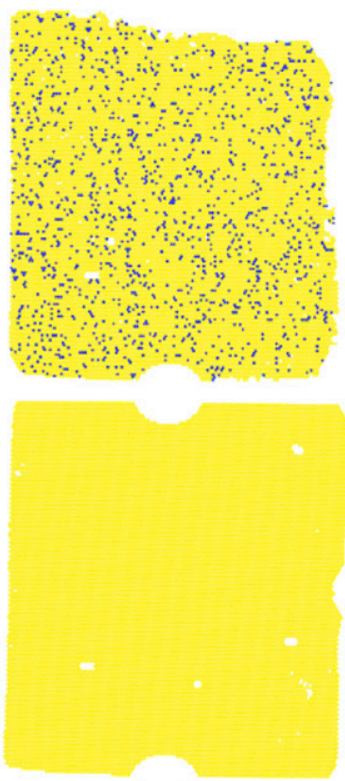

$1 \mathrm{e}-8$
$1 \mathrm{e}-4$

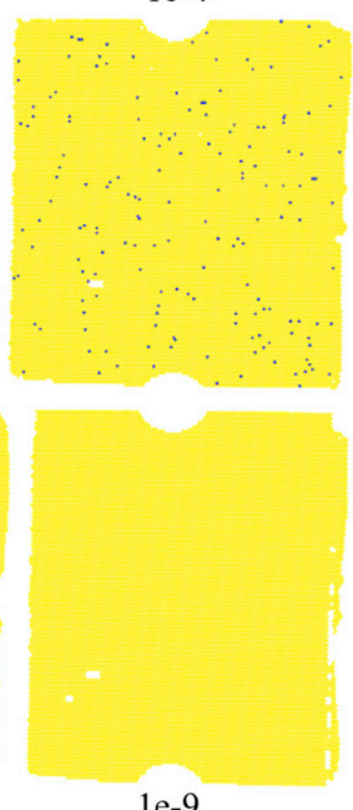

1e-9

Fig. 2. Digital chip images for TaqMan assays to detect the 16SrIV-A phytoplasma in a dilution series.

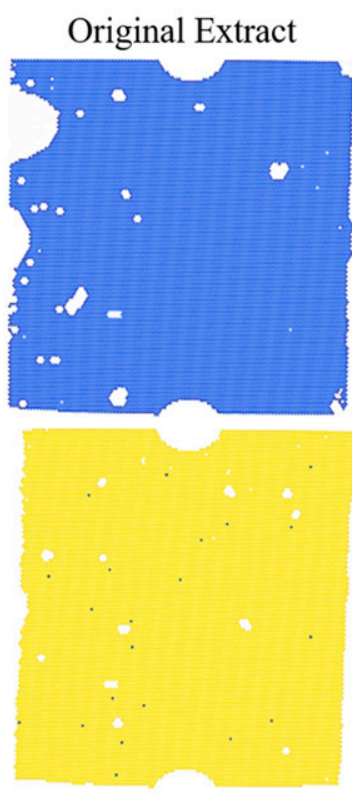

1e-5 1e-1
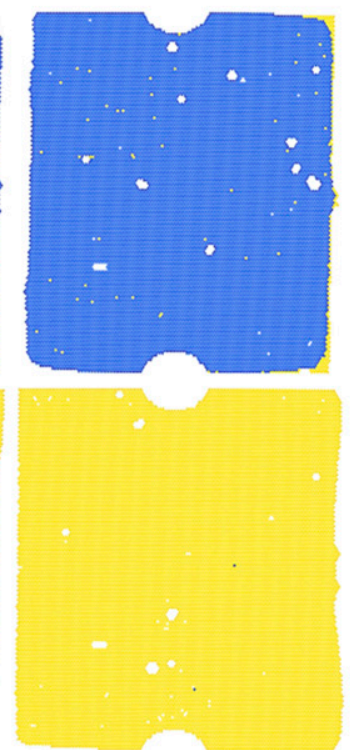

$1 \mathrm{e}-6$

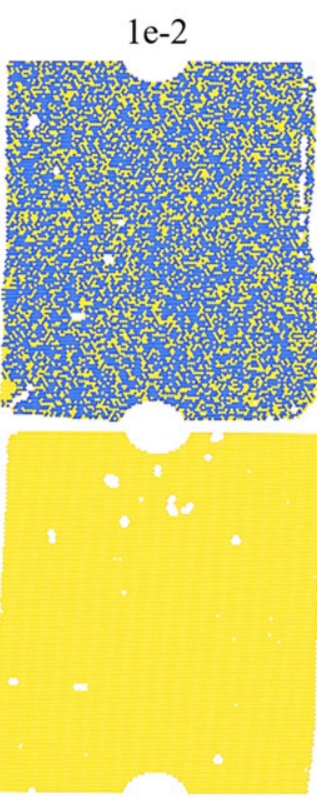

1e-7

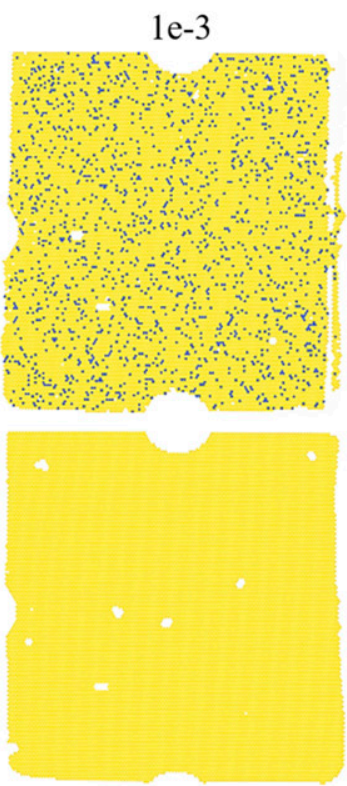

1e- 8

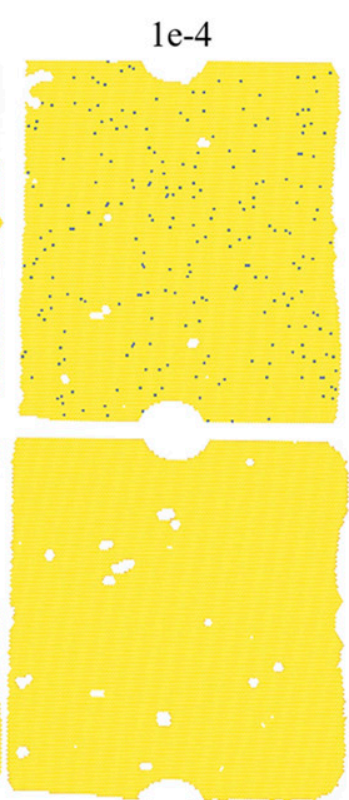

1e-9

Fig. 3. Digital chip images for TagMan assays to detect the 16SrIV-B phytoplasma in a dilution series. 
dPCR assay data and chip images. The TaqMan assay successfully amplified the target region for the 16SrIV-A phytoplasma (Table 2), the 16SrIV-B phytoplasma (Table 3) and the 16SrIV-D phytoplasma (Table 4). The original extract for the 16SrIV-A isolate had a high enough titer of phytoplasma to fully saturate the dPCR chip, resulting in amplification success of all wells passing the assay quality threshold (Fig. 2). Additionally, the first serial dilution for the 16SrIV-A isolate was too concentrated and also yielded a fully saturated chip with all wells passing threshold exhibiting amplification (Fig. 2). The optimal reaction for 16 SrIV-A was the $1 \mathrm{e}^{-2}(1 \%$ diluted from original extract) dilution, with the pathogen being detectable at the $1 \mathrm{e}^{-6}$ dilution $(0.0001 \%$ diluted from original extract) (Fig. 2$)$. This reaction allowed for the most accurate estimate of phytoplasma amplicon target copies per microliter; estimates of copies per microliter in the original extract could not be calculated from the original extract itself or the $1 \mathrm{e}^{-1}$ dilution due to complete saturation of the chip with target DNA. The $1 \mathrm{e}^{-7}, 1 \mathrm{e}^{-8}$, and $1 \mathrm{e}^{-9}$ dilution reactions also did not provide estimates of copies per microliter for the original extract due to no positive reactions on the chips. The $1 \mathrm{e}^{-3}, 1 \mathrm{e}^{-4}, 1 \mathrm{e}^{-5}$, and $1 \mathrm{e}^{-6}$ all provided an estimate of the copies per microliter of the original extract (Table 2) but were not as accurate as the $1 \mathrm{e}^{-2}$ reaction and with accuracy decreasing as samples became more diluted (Table 2).

For the 16SrIV-B phytoplasma, the original extract possessed a high enough titer to fully saturate the chip (Fig. 3). The first dilution $\left(1 \mathrm{e}^{-1}\right)$ was also highly saturated; however, there were a small number (227) of wells with no amplification (Fig. 3). The optimal dilution for detection was the $1 \mathrm{e}^{-2}$ dilution that yielded high precision (Fig. 3). This dilution factor contained total DNA at approximately $0.7 \mathrm{ng} / \mu \mathrm{l}$ (Table 1). The lowest dilution factor testing positive was the $1 \mathrm{e}^{-6}$ factor, yielding two positive wells but very low precision (Fig. 3). After this dilution, no reactions yielded positive amplification (Fig. 3).

For the 16SrIV-D phytoplasma serial dilution, the original extract had a high enough titer to fully saturate the chip (Fig. 4). The $1 \mathrm{e}^{-1}$ dilution reaction displayed near complete saturation of the chip but did show some wells as negative (no target and no amplification) (Fig. 4). The $1 \mathrm{e}^{-3}$ dilution reaction was the optimal reaction (Fig. 4), with the pathogen detectable down to the $1 \mathrm{e}^{-6}$ dilution reaction $\left(0.0001 \%\right.$ diluted from original extract). At the $1 \mathrm{e}^{-7}, 1 \mathrm{e}^{-8}$, and $1 \mathrm{e}^{-9}$ dilution reactions, the phytoplasma was undetectable (Fig. 4). For estimates of copies per microliter, the $1 \mathrm{e}^{-2}$ gave the most accurate estimate (Table 4 ) whereas the $1 \mathrm{e}^{-1}$ reaction yielded an estimate with low accuracy (Table 4) due to the disproportionate number of positive wells to negative wells (Table 4). Estimates for copies per microliter were also given for the $1 \mathrm{e}^{-3}, 1 \mathrm{e}^{-4}, 1 \mathrm{e}^{-5}$, and $1 \mathrm{e}^{-6}$ dilution reactions, with decreasing accuracy from the $1 \mathrm{e}^{-2}$ reaction due to samples becoming too diluted for detection (Table 4). An estimate of copies per microliter of the original extract from the reaction using original extract was not given due to a high titer, resulting in complete saturation of the chip (Table 4). The $1 \mathrm{e}^{-7}, 1 \mathrm{e}^{-8}$, and $1 \mathrm{e}$ ${ }^{-9}$ dilution reactions also did not yield estimates of copies per microliter for the original extract due to negative reactions across the entire chip (Table 4).

Based on amplification success in the 16SrIV isolates, dilution factors of the 16SrI and 16SrIII phytoplasmas that had comparable total DNA concentrations as the optimal reactions for the 16SrIV isolates were tested. Based on this, the $1 \mathrm{e}^{-4}$ was selected for the $16 \mathrm{SrI}$ isolate and the $1 \mathrm{e}^{-3}$ was selected for the $16 \mathrm{SrIII}$ isolate which contained $0.7 \mathrm{ng} / \mu \mathrm{l}$ and $5.3 \mathrm{ng} / \mu \mathrm{l}$ respectively of total DNA. Both tests against these non 16SrIV phytoplasmas yielded high amplification success (Fig. 5) and good precision (Table 5).

Isolate dilution real-time PCR data. The 16SrIV-A isolate was detectable reliably by real-time PCR at the $1 \mathrm{e}^{-3}$ dilution factor $(0.1 \%$ of the original extract), with all five replicates amplifying
$16 \mathrm{SrI}$

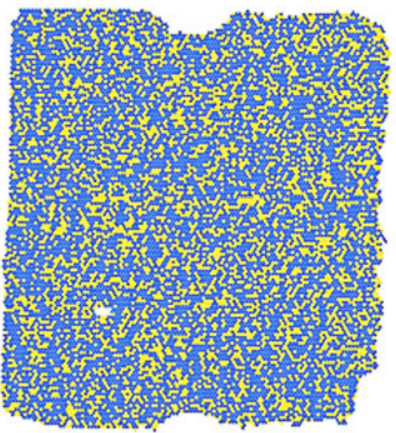

$16 \mathrm{SrIII}$

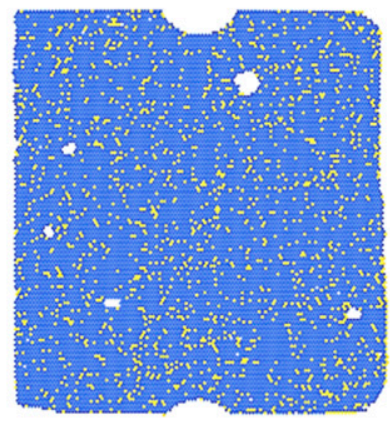

Fig. 5. Digital chip images for the TaqMan assay designed for 16SrlV phytoplasmas used in amplification of $16 \mathrm{Srl}$ and $16 \mathrm{Sr}$ rll phytoplasmas.

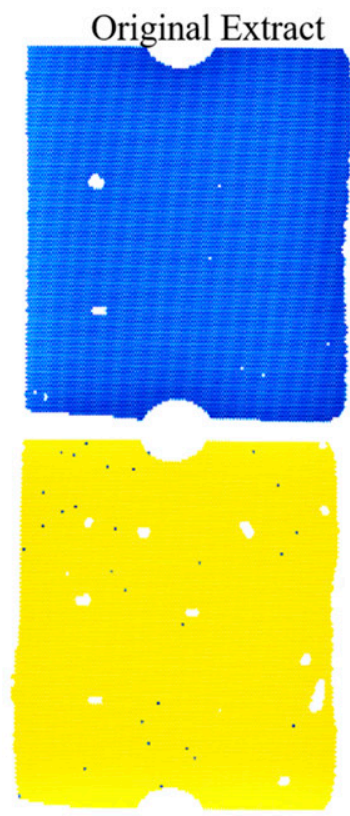

$1 e-5$
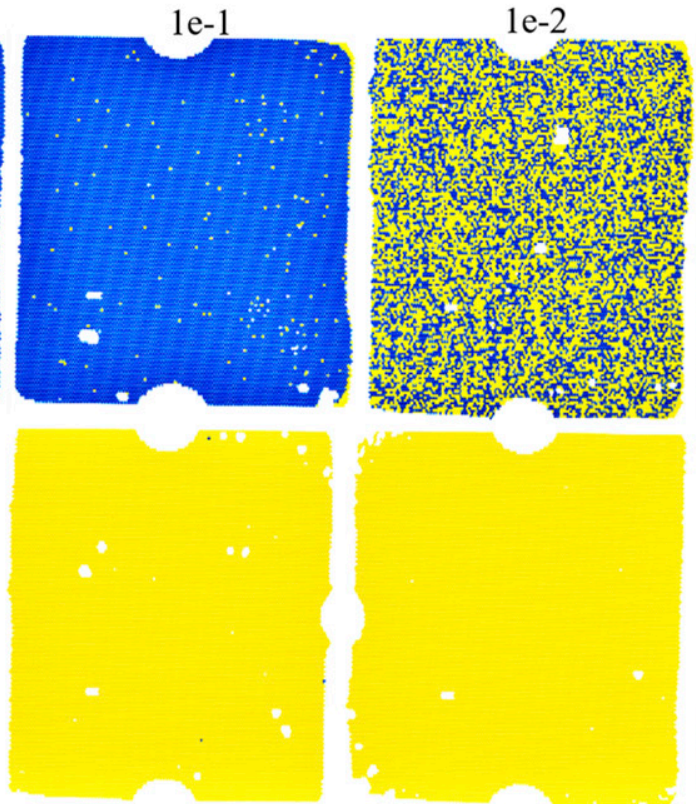

$1 e-6$

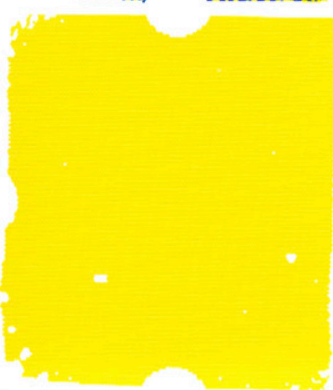

$1 \mathrm{e}-7$

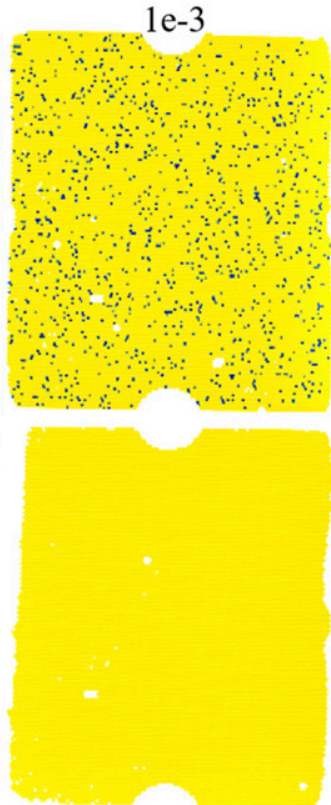

$1 \mathrm{e}-8$

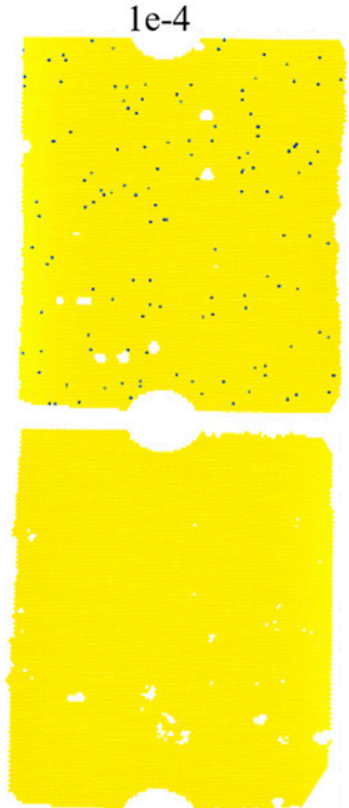

1e-9

Fig. 4. Digital chip images for TaqMan assays to detect the16SrIV-D phytoplasma in a dilution series. 
(Table 6), and began to fail at the $1 \mathrm{e}^{-4}$ dilution factor $(0.01 \%$ of the original extract), with three of the five replicates successfully amplifying and yielding a cycle threshold $(\mathrm{Ct})$ value greater than 30 . Complete failure to amplify phytoplasma DNA began at the $1 \mathrm{e}^{-5}$ dilution factor $(0.001 \%$ of original extract) and all subsequent dilutions tested negative (Table 6). The 16SrIV-D isolate was detectable reliably at the $1 \mathrm{e}^{-2}$ dilution factor (1.0\% dilution from original extract), with all five replicates amplifying successfully (Table 6). Phytoplasma DNA was still detectable at the $1 \mathrm{e}^{-3}$ dilution factor $(0.1 \%$ dilution from original extract) but amplified in four of the five replicates yielding a $\mathrm{Ct}$ value greater than 30 (Table 6). Phytoplasma DNA was completely undetectable beginning at the $1 \mathrm{e}^{-4}$ dilution factor ( $0.01 \%$ dilution of original extract) and target DNA was undetectable in subsequent dilutions (Table 6). All healthy controls and water controls tested negative (Table 6).

Isolate dilution nested PCR data. Standard nested PCR assay was able to detect the $16 \mathrm{SrIV}-\mathrm{A}$ isolate from total DNA through dilution factor $1 \mathrm{e}^{-4}(0.01 \%$ of the original extract) (Fig. 6). Subsequent dilutions were undetectable using the nested PCR protocol. For 16SrIV-D isolate dilutions, amplification was only present from

Table 5. Digital polymerase chain reaction data for other phytoplasmas outside the 16SrIV group

\begin{tabular}{lcc}
\hline Parameters & 16SrI & 16SrIII \\
\hline Total wells & 17,084 & 17,469 \\
$(+)$ Wells & 11,299 & 15,610 \\
$(-)$ Wells & 5,785 & 1,859 \\
Copies $/ \mu l$ & $1,440.2$ & $2,989.4$ \\
Precision $(\%)$ & 2.13 & 1.95 \\
\hline
\end{tabular}

Table 6. Real-time polymerase chain reaction (PCR) data for serial dilutions of the 16SrIV-A and 16SrIV-D phytoplasmas used in the digital PCR TaqMan assays

\begin{tabular}{|c|c|c|c|c|}
\hline \multirow[b]{2}{*}{ Dilution } & \multicolumn{4}{|c|}{ Cycle threshold $(\mathrm{Ct})$ value $^{\mathrm{a}}$} \\
\hline & 16SrIV-A & 16SrIV-D & Healthy control & Water control \\
\hline 1 & $18.9 \pm 0.3$ & $16.5 \pm 0.1$ & No Ct & No Ct \\
\hline $1 \mathrm{e}^{-1}$ & $22.1 \pm 0.2$ & $23.5 \pm 0.1$ & $\mathrm{No} C t$ & N/A \\
\hline $1 \mathrm{e}^{-2}$ & $26.9 \pm 0.3$ & $27.7 \pm 0.02$ & $\mathrm{No} C t$ & N/A \\
\hline $1 \mathrm{e}^{-3}$ & $30.4 \pm 0.2$ & $32.0 \pm 0.1^{\mathrm{b}}$ & $\mathrm{No} C t$ & N/A \\
\hline $1 \mathrm{e}^{-4}$ & $34.8 \pm 0.2^{c}$ & $\mathrm{No} C t$ & $\mathrm{No} C t$ & N/A \\
\hline $1 \mathrm{e}^{-5}$ & No Ct & No Ct & No Ct & N/A \\
\hline $1 \mathrm{e}^{-6}$ & $\mathrm{No} C t$ & $\mathrm{No} C t$ & No Ct & N/A \\
\hline $1 \mathrm{e}^{-7}$ & No Ct & No Ct & No Ct & N/A \\
\hline $1 e^{-8}$ & No Ct & No Ct & $\mathrm{No} C t$ & N/A \\
\hline $1 \mathrm{e}^{-9}$ & No $\mathrm{Ct}$ & No $\mathrm{Ct}$ & No $\mathrm{Ct}$ & N/A \\
\hline
\end{tabular}

${ }^{\mathrm{a}} \mathrm{N} / \mathrm{A}=$ not available

${ }^{\mathrm{b}}$ One of five replicates did not amplify, resulting in No Ct.

${ }^{c}$ Two of five replicates did not amplify, resulting in No Ct. the total DNA through the $1 \mathrm{e}^{-2}$ dilution factor (1.0\% dilution from original extract) (Fig. 6). Phytoplasma DNA was not detected in the healthy control at any of the dilution factors and all water controls tested negative (Fig. 6).

\section{Discussion}

Based on the results of this study, the TaqMan assay presented herein reliably amplifies target DNA for the 16SrIV-A, 16SrIV-B, and 16SrIV-D phytoplasmas as well as phytoplasmas belonging to the $16 \mathrm{SrI}$ and $16 \mathrm{SrIII}$ groups. Based on the sequence similarity of the assay's primer annealing sites among phytoplasma strains belonging to both these and other subgroups in group 16SrIV, as well as other phytoplasmas classified in other $16 \mathrm{Sr}$ groups, this assay should be capable of detecting phylogenetically widely diverse phytoplasmas, and possibly all phytoplasmas. Based on these results, it also appears that the optimal concentration for detection of palminfecting phytoplasmas from infected plants is total DNA at between 0.5 and $1.0 \mathrm{ng} / \mu \mathrm{l}$. The data also show that this assay used with $\mathrm{dPCR}$ is more sensitive than real-time PCR and standard nested PCR assays, allowing for detection of phytoplasma DNA at two dilution factors more in the dPCR assays in the case of the 16SrIV-A isolate and three dilution factors more in the case of 16SrIV-D isolate. The difference in detection between the two isolates for the real-time PCR assays is likely due to different concentration of phytoplasma in the eluate that could be the result of different sampling methods and extraction methods that were used for the 16SrIV-A and 16SrIV-D isolates, respectively. Regardless, in both instances, dPCR was more sensitive for detection of phytoplasma DNA in the respective samples. The chip-based dPCR system used in this study possesses 20,000 wells that are 755 picoliters in volume. The reaction mixture uses $6 \mu 1$ of template that is then distributed over the 20,000 wells. The $14.5-\mu 1$ reaction mixture that includes the template, probe, and master mix is thus partitioned into 20,000 separate PCR for the same sample. Based on the amount of template and the number of wells, each individual PCR relies on a volume of template that is $3.9 \%$ of the total volume. In contrast, qPCR rely on templates representing $5.0 \%$ of the reaction volume. This implies that dPCR would be more sensitive still if the qPCR assays in this study had been adjusted to have the same percentage of template per reaction as was present in the dPCR chip wells.

These results are consistent with findings from other studies that compare dPCR assays to qPCR assays for evaluating mtDNA deletions (Belmonte et al. 2016) and KRAS mutations in colorectal cancer patients (Taly et al. 2013), and for detection of HIV in humans (Strain et al. 2013), and found that dPCR was more sensitive for target detection from an applied perspective. Although chip-based dPCR has been used for the detection of viruses in plants (Bahder et al. 2016), this is the first use of chip-based dPCR for the detection of phytoplasmas in plant tissue.

The increased sensitivity of dPCR over qPCR and standard nested PCR assays will allow for earlier detection of phytoplasmas in palm. Currently, the time between inoculation and onset of symptoms for both the 16SrIV-A and 16SrIV-D phytoplasmas in palm hosts is

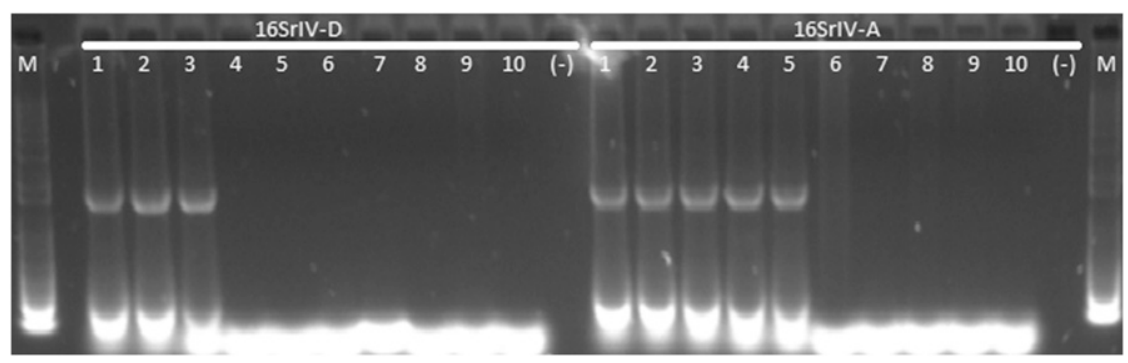

Fig. 6. Nested polymerase chain reaction (PCR) product run on a 1.5\% agarose stained with GelRed for the 16SrIV-A and 16SrIV-D phytoplasma dilution series used in digital PCR and real-time PCR assays: lane $1=$ undiluted eluate, lane $2=1 \mathrm{e}^{-1}$, lane $3=1 \mathrm{e}^{-2}$, lane $4=1 \mathrm{e}^{-3}$, lane $5=1 \mathrm{e}^{-4}$, lane $6=1 \mathrm{e}^{-5}$, lane $7=1 \mathrm{e}^{-6}$, lane $8=1 \mathrm{e}^{-7}$, lane $9=1 \mathrm{e}^{-8}$, lane $10=1 \mathrm{e}^{-9}$, and lane $(-)=$ water control. 
unknown. Phytoplasma DNA is easily detectable in trunk tissue once symptoms are apparent but is undetectable using current methods in healthy-appearing trees that later become symptomatic (N. A. Harrison, unpublished data). This assay will allow for a more accurate understanding and monitoring of disease progression in infected palm and palm trees that are at risk. Also, being able to detect phytoplasma in this latent phase before plants become symptomatic will allow for earlier implementation of management decisions such as removing the palm or treating with oxytetracycline. Effective management of diseased palm trees earlier will also reduce the risk of spread of the phytoplasma in the environment by the vector. Although the increased sensitivity of dPCR provides a valuable tool for addressing basic questions about the epidemiology of LBD, it is not optimal at this time for use as a diagnostic tool for stakeholders due to the high cost of materials per sample. Currently, qPCR remains the cheapest and fastest method from a diagnostic perspective. Despite the current high cost of running dPCR assays, current research is focusing on the development of protocols that would allow dPCR to be used in a costeffective manner that will benefit palm growers.

In addition to being able to detect lower titers of phytoplasma in plant host tissue, this assay should be useful for detecting phytoplasma DNA in insect vectors. This level of sensitivity is valuable because it may allow for the screening of a candidate vector by using the hemolymph and salivary glands, which can aide in vector discovery. For the 16SrIV-D strain of phytoplasma causing LBD, a vector has not been identified and the putative vector for the 16SrIV-A phytoplasma which causes LY is Haplaxius crudus (Howard and Thomas 1980, Howard et al. 1983). Although the status of H. crudus as a vector of LY is generally accepted, it is not known if other, less common, species within the genus Haplaxius or species in other closely related genera are capable of transmitting the 16SrIV-A phytoplasma. Being able to rapidly screen potential insect vectors for their capacity to transmit phytoplasma (presence in salivary glands) should allow for more efficient transmission assays that eliminate conducting experiments on species that cannot truly acquire the phytoplasma. Due to the extended period of time between inoculation and initial detection of a phytoplasma in palm, as well as the generally large size of infected palm trees, transmission assays are logistically difficult and it is not cost effective to screen many different insect species in this manner. By screening salivary glands for the presence or absence of phytoplasma DNA, transmission assays can focus only on insect species that can acquire the pathogen in the salivary glands and, thus, would be most likely to transmit the phytoplasma to a new host.

Overall, the development of a TaqMan assay for use with dPCR to detect phytoplasmas in palm allows for a higher degree of sensitivity. This increased sensitivity will allow for earlier detection in infected palm trees and potentially prior to symptom onset, earlier confirmation of new infections either occurring in the field or from transmission assays, as well as detection of phytoplasma in vector candidate species. By detecting infections sooner, proper management practices can be implemented quickly to reduce the amount of time the inoculum is present in the environment, thus reducing the probability of further spread.

\section{Literature Cited}

Bahder, B. W., Helmick, E. E., and Harrison, N. A. 2017. Detecting and differentiating phytoplasmas belonging to subgroups 16SrIV-A and 16SrIV-D associated with lethal declines in palms in Florida using qPCR and highresolution melt analysis (HRMA). Plant Dis. 101:1449-1454.
Bahder, B. W., Zalom, F. G., Jayanth, M., and Sudarshana, M. R. 2016. Phylogeny of geminivirus coat protein sequences and digital PCR aid in identifying Spissistilus festinus as a vector of grapevine red blotch-associated virus. Phytopathology 106:1223-1230.

Belmonte, F. R., Martin, J. L., Frescura, K., Damas, J., Pereira, F., Tarnopolosky, M. A., and Kaufman, B. A. 2016. Digital PCR methods improve detection sensitivity and measurement precision of low abundance mtDNA deletions. Sci. Rep. 6: Article 25186.

Bertaccini, A., Duduk, B., Paltinieri, S., and Contaldo, N. 2014. Phytoplasmas and phytoplasma diseases: A severe threat to agriculture. Am. J. Plant Sci. 5: 1763-1788.

Corbett, M. K. 1959. Diseases of the coconut palm. Principes 3:5-13.

Córdova, I., Oropeza, C., Puch-Hau, C., Harrison, N., Collí-Rodríguez, A., Narvaez, M., Nic-Matos, G., Reyes, C., and Sáenz, L. 2014. A real-time PCR assay for detection of coconut lethal yellowing phytoplasmas of group 16SrIV subgroups A, D and E found in the Americas. J. Plant Pathol. 96: 343-352.

Dreo, T., Pirc, M., Ramšak, Ž., Pavšič, J., Milavec, M., Žel, J., and Gruden, K. 2014. Optimising droplet digital PCR analysis approaches for detection and quantification of bacteria: A case study of fire blight and potato brown rot. Anal. Bioanal. Chem. 406:6513-6528.

Harrison, N. A., and Elliott, M. L. 2015. Lethal Yellowing (LY) of Palm. UF/IFAS Ext. Publ. PP-222.

Harrison, N. A., and Elliott, M. L. 2016. Texas Phoenix Palm Decline. UF/IFAS Ext. Publ. PP243.

Harrison, N. A., Helmick, E. E., and Elliott, M. L. 2008. Lethal yellowing-type diseases of palms associated with phytoplasmas newly identified in Florida, USA. Ann. Appl. Biol. 153:85-94.

Harrison, N. A., Narváez, M., Almeyda, H., Cordova, I., Carpio, M. L., and Oropeza, C. 2002a. First report of group 16SrIV phytoplasmas infecting coconut palms with leaf yellowing symptoms on the Pacific coast of Mexico. Plant Pathol. 51:808.

Harrison, N. A., Richardson, P. A., Kramer, J. B., and Tsai, J. H. 1994. Detection of the mycoplasma-like organism associated with lethal yellowing disease of palms in Florida by polymerase chain reaction. Plant Pathol. 43:998-1008.

Harrison, N. A., Womack, M., and Carpio, M. L. 2002b. Detection and characterization of a lethal yellowing (16SrIV) group phytoplasma in Canary Island date palms affected by lethal decline in Texas. Plant Dis. 86:676-681.

Howard, F. W., Norris, R. C., and Thomas, D. L. 1983. Evidence of transmission of palm lethal yellowing agent by a planthopper, Myndus crudus (Homoptera: Cixiidae). Trop. Agric. Trinidad 60:168-171

Howard, F. W., and Thomas, D. L. 1980. Transmission of palm lethal decline to Veitchia merrillii by a planthopper Myndus crudus. J. Econ. Entomol. 73: 715-717.

McCoy, R. E., Miller, M. E., Thomas, D. L., and Amador, J. 1980. Lethal decline of Phoenix palms in Texas associated with mycoplasma-like organisms. Plant Dis. 64:1038-1040.

Miotke, L., Lau, B. T., Rumma, R. T., and Ji, H. P. 2014. High sensitivity detection and quantitation of DNA copy number and single nucleotide variants with single copy droplet digital PCR. Anal. Chem. 86:2618-2624.

Rački, N., Dreo, T., Guiterrez-Aguirre, I., Blejec, A., and Ravnikar, M. 2014 Reverse transcriptase droplet digital PCR shows high resilience to PCR inhibitors from plant, soil and water samples. Plant Methods 10:42.

Strain, M. C., Lada, S. M., Luong, T., Rought, S. E., Gianella, S., Terry, V. H., Spina, C. A., Woelk, C. H., and Richman, D. D. 2013. Highly precise measurement of HIV DNA by droplet digital PCR. PLoS One 8:e55943.

Taly, V., Pekin, D., Benhaim, L., Kotsopoulos, S. K., Le Corre, D., Li, X., Atochin, I., Link, D. R., Griffiths, A. D., Pallier, K., Blons, H., Bouché, O., Landi, B., Hutchison, J. B., and Laurent-Puig, P. 2013. Multiplex picodroplet digital PCR to detect KRAS mutations in circulating DNA from the plasma of colorectal cancer patients. Clin. Chem. 59:1722-1731.

Thomas, D. L. 1974. Possible link between declining palm species and lethal yellowing of coconut palms. Proc. Fla. State Hortic. Soc. 87:502-504.

Tymon, A. M., Jones, P., and Harrison, N. A. 1998. Phylogenetic relationships of coconut phytoplasmas and the development of specific oligonucleotide PCR primers. Ann. Appl. Biol. 132:437-452.

Vázquez-Euán, R., Harrison, N., Narvaez, M., and Oropeza, C. 2011. Occurrence of a 16SrIV group phytoplasma not previously associated with palm species in Yucatan, Mexico. Plant Dis. 95:256-262.

Weintraub, P. G., and Beanland, L. 2006. Insect Vectors of Phytoplasmas. Annu. Rev. Entomol. 51:91-111. 